\title{
Evaluation of methods of assisted ventilation in hyaline membrane disease
}

\author{
FRANK P. MANGINELLO, ARMANDO E. GRASSI, SYLVIA SCHECHNER, \\ ALFRED N. KRAUSS, AND PETER A. M. AULD \\ From the Perinatology Center and Department of Paediatrics, The New York Hospital, \\ Cornell Medical Center, New York
}

SUMMARY Two methods of providing assisted ventilation were compared in infants severely ill with hyaline membrane disease (HMD). 10 infants were assigned to each group. One group received ventilation with a volume-cycled respirator, and the other was ventilated using a pressure-limited ventilator and reversed I:E ratio. Both groups were well matched for severity of illness in terms of $\mathrm{pH}$ and blood gases. $\mathrm{pH}$ and $\mathrm{Po}_{2}$ were quickly corrected by both ventilators. However, the pressurecycled ventilator group had higher survival and lower complication rates. $\mathrm{PaO}_{2}$ after one hour was substantially improved at the same $\mathrm{F}_{\mathrm{I}} \mathrm{O}_{2}$ in the pressure-limited group and after 8 hours the $\mathrm{F}_{\mathrm{I}} \mathrm{O}_{2}$ required to maintain a $\mathrm{PaO}_{2}$ of $50-70 \mathrm{mmHg}(6 \cdot 6-9 \cdot 3 \mathrm{kPa})$ was significantly decreased compared with the volume-cycled group. No effects on blood pressure were detected in either group. The study shows that the pressure-limited method is significantly better.

The principal objectives of mechanical ventilation in hyaline membrane disease (HMD) are to improve oxygenation and relieve acidosis while minimising damage to the lung. In most cases, arterial blood gases can be stabilised but often complicationssuch as bronchopulmonary dysplasia (BPD), interstitial emphysema, and pneumothorax-may complicate recovery and eventually delay weaning from the respirator.

It has been suggested that infants can be successfully ventilated with fewer complications by limiting peak airways pressure (Herman and Reynolds, 1973). This can be done by using a low respiratory rate and a reversal of the usual inspiratory:expiratory (I:E) ratio. This method, which uses a prolonged inspiratory time, may enable recruitment of collapsed alveoli and improve the ventilation of areas with varying time constants. No adverse effects on the circulation were noted. Other reports have shown that ventilation of newborn babies with low lung compliance by reversed $\mathrm{I}: \mathrm{E}$ ratios can improve oxygenation, although $\mathrm{CO}_{2}$ retention was observed in some cases (Keuskamp, 1974). An optimal I:E ratio that gives adequate oxygenation and avoids hypercarbia and circulatory effects can be determined only by trial and error for each patient.

Received 6 January 1978
Complications occur frequently in mechanicallyventilated patients. Pleural air leaks are the most common and have been reported in as many as $40 \%$ of patients in one study (Berg et al., 1975). The reason for this high incidence is unknown but high pressures delivered to overdistended alveoli may produce rupture. BPD may be related to the trauma that results from high peak airways pressure, although oxygen toxicity may be a factor.

This study was carried out to compare the effects of pressure-limited ventilation, as advocated by Herman and Reynolds, with ventilation regulation by volume in which there is no pressure limit. Although mean airways pressure is the same in both methods, the peak pressure applied to the airways, the I:E ratio, and respiratory rate differ. Effectiveness of ventilation, oxygenation, and incidence was compared in the two methods.

\section{Material and methods}

Twenty newborn infants with a diagnosis of severe HMD admitted to the New York Hospital, Cornell Medical Center Neonatal Intensive Care Unit during a 3-month period were studied. All infants were initially treated with oxygen delivered by hood. Constant positive airways pressure (CPAP) was administered by nasal prongs, or bag 

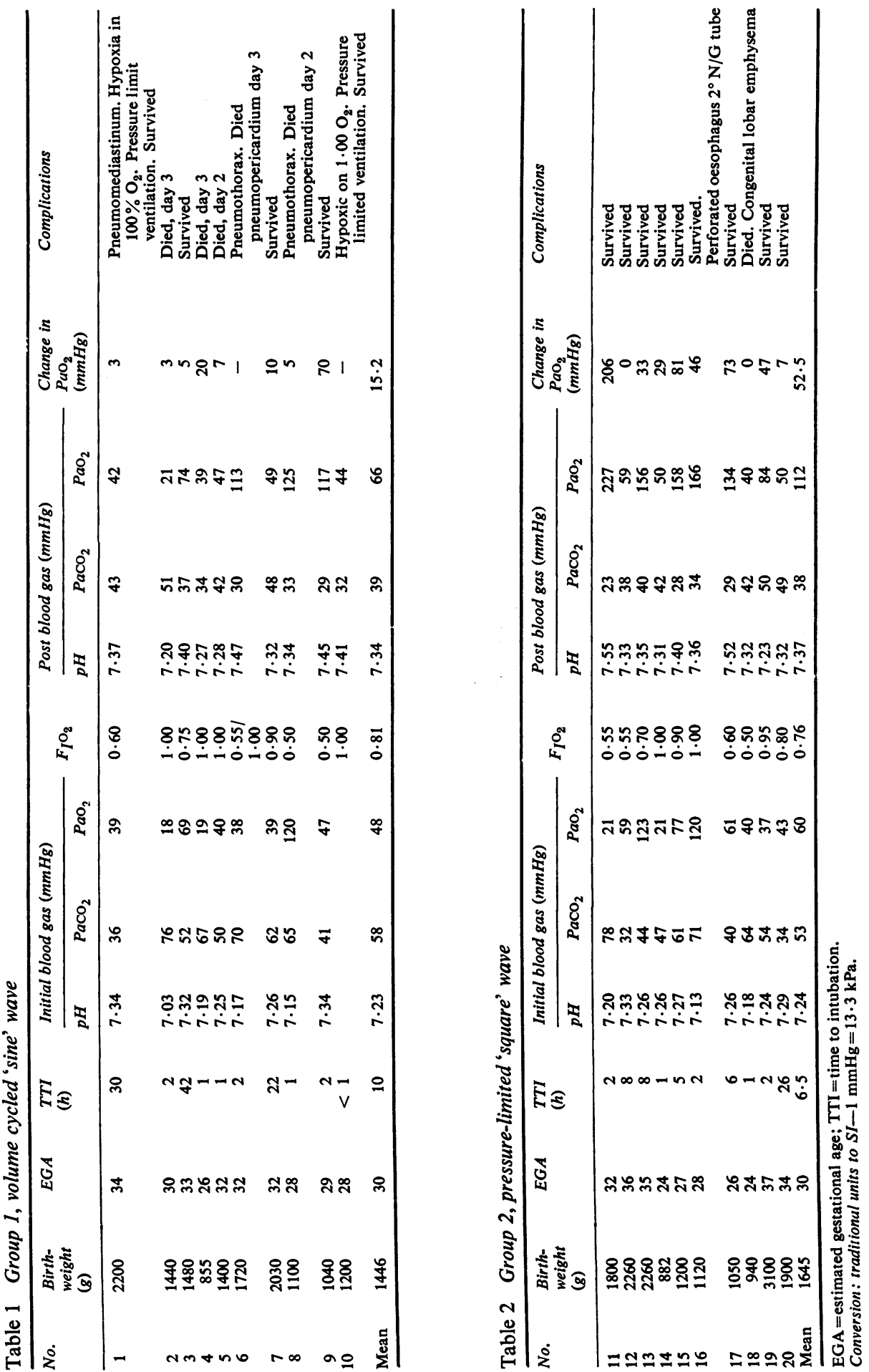
and mask, when the $\mathrm{PaO}_{2}$ was $<50 \mathrm{mmHg}$ $(<6.6 \mathrm{kPa})$ with $\mathrm{F}_{\mathrm{IO}_{2}}>0.60$ and the infant breathing spontaneously. Mechanical ventilation was begun when respiratory failure occurred, as diagnosed by one or more of the following criteria: pH less than 7.25 and $\mathrm{PCO}_{2}>60 \mathrm{mmHg}(>7.9 \mathrm{kPa})$, $\mathrm{PaO}_{2}<50 \mathrm{mmHg}$ with $\mathrm{FIO}_{2}>0 \cdot 80$, cardiopulmonary arrest, recurrent apnoea, and bradycardia. These indications for assisted ventilation were used for all infants in this study. Intubation was carried out with Portex nasotracheal tubes or Rusch orotracheal tubes.

Infants were randomly assigned to either a volume-cycled or pressure-cycled respirator. 10 patients (group 1) were placed on volume-cycled ventilation (Bournes LS 104-150). Tidal volume was 8-10 $\mathrm{ml}$, $\mathrm{kg}$, plus an allowance for tubing compliance, and respiratory rate was set at 30 breaths $/ \mathrm{min}$. This ventilator generates a peak airways pressure as shown in Fig. 1a. Mean in vivo pressure for all infants in this group was $42 \mathrm{cmH}_{2} \mathrm{O}(4 \cdot 1 \mathrm{kPa})$ with a range of $30-50 \mathrm{cmH}_{2} \mathrm{O}(2 \cdot 9-4 \cdot 9 \mathrm{kPa})$.

If blood gases and $\mathrm{pH}$ were not normalised within 2 hours or if babies remained hypoxic, i.e. $\mathrm{PaO}_{2}<50$ $\mathrm{mmHg}$ with $\mathrm{F}_{\mathrm{IO}_{2}}>0.80$, the technique was considered a failure and the alternate method was begun. 10 infants (group 2) were placed on a pressure-cycled respirator (Bournes BP-200) adjusted to a pressure limit of $25 \mathrm{cmH}_{2} \mathrm{O}(2.4 \mathrm{kPa})$ on a I:E ratio of $1: 1$ with a respiratory rate set at 30
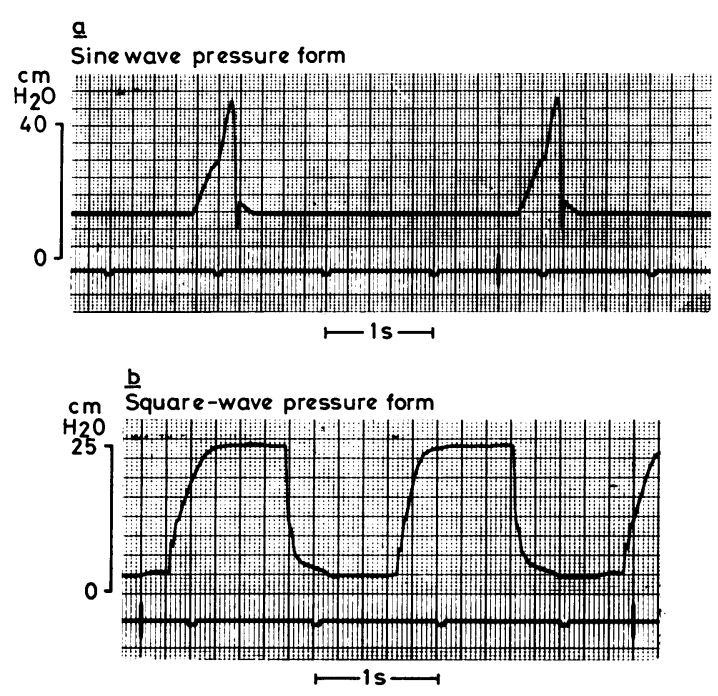

Figs 1a, b Pressure wave form generated by (a) volume-cycled and (b) pressure-limited wave respirators. breaths/min. This respirator mode generated a peak airways pressure as shown in Fig. 1b. Identical criteria for failure were applied as in group 1: In both groups, each patient received a $5 \mathrm{cmH}_{2} \mathrm{O}$ (490 $\mathrm{Pa}$ ) positive end expiratory pressure. All infants in both groups received an initial breath rate of $30 / \mathrm{min}$. Respiration was controlled in all cases. Intermittent mandatory ventilation was used to wean infants from the respirator. Blood gases were monitored through a catheter in the umbilical artery.

The two methods of mechanical ventilation were evaluated as follows: (1) the change in $\mathrm{PaO}_{2}$ immediately before and one hour after mechanical ventilation was begun at constant $\mathrm{F}_{\mathrm{I}} \mathrm{O}_{2}$ (one-way analysis of variance), (2) the change in $\mathrm{F}_{\mathrm{IO}}$ required to maintain $\mathrm{PaO}_{2}$ at between 50 and $70 \mathrm{mmHg}$ during the first 8-hour period of mechanical ventilation.

\section{Results}

Clinical data, including birthweight, estimated gestational age, and arterial blood gases at time of admission to the study are presented in Tables 1 and 2. No statistically significant difference was found between the two groups using Student's $t$ test. Infants in group 1 required mechanical ventilation for a mean of 208 hours, with a range of 144 to 240 hours. Infants in group 2 required a mean of 130 hours of assisted ventilation, with a range of 65 to 221 hours.

Pressure-limited ventilation was as effective as volume-cycled ventilation in rapidly correcting $\mathrm{pH}$ and arterial $\mathrm{PCO}_{2}$. Comparisons of arterial $\mathrm{PO}_{2}$ in the two groups indicated that the pressure-limited ventilator was more effective with a mean $\mathrm{PaO}_{2}$ value of $52 \mathrm{mmHg}(6.9 \mathrm{kPa})$ in group 2 compared with $15 \mathrm{mmHg}(1.9 \mathrm{kPa})$ in group $1(\mathrm{P}<0.001)$.

Infants in group 1 showed a slight increase in oxygen requirement 8 hours after mechanical ventilation began (mean $\mathrm{F}_{\mathrm{I}} \mathrm{O}_{2} \mathbf{0 . 7 8}$ to 0.85 ), whereas a significantly decreased $\mathrm{F}_{1} \mathrm{O}_{2}$ was required to maintain arterial $\mathrm{Po}_{2}$ in group 2 (mean $\mathrm{F}_{\mathrm{IO}} \mathrm{O}_{2} 0.79$ to 0.61 ), $P<0.05$ : Fig. 2 .

Three of 10 patients in group 1 were eventually weaned from the volume-cycled respirator. Five died, all of whom showed changes at post-mortem examination compatible with bronchopulmonary dysplasia. Two patients in group 1 who remained hypoxaemic at an $\mathrm{F}_{\mathrm{IO}} \mathrm{O}_{2}$ of 1.0 with a volume-cycled respirator were successfully managed on a pressurelimited ventilator. Three of the 10 patients in group 1 sustained air leaks.

Nine of 10 patients in group 2 were successfully weaned from their ventilators. This difference in survival, in terms of successful weaning, was statistically significant $(P<0 \cdot 01)$. One infant in the 


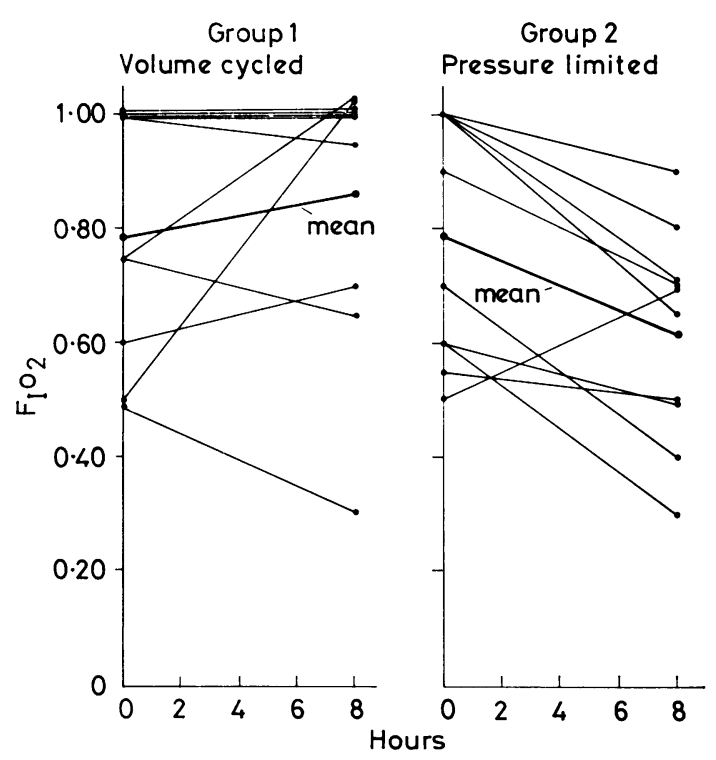

Fig. 2 Change in $\mathrm{F}_{\mathrm{I}} \mathrm{O}_{2}$ to maintain $\mathrm{PaO}_{2} 50-70 \mathrm{mmHg}$ $(6.6-9.3 \mathrm{kPa})$ after 8 hours of (a) volume-cycled and (b) pressure-limited respirator.

pressure-limited group expired with rapidly expanding congenital lobar emphysema, confirmed at necropsy. The differences in mortality rates $(3 / 10$ in group 1 v. $0 / 10$ in group 2) were not significant statistically $(\mathrm{P}<0 \cdot \mathrm{c6})$.

None of the infants receiving increased I:E ratios experienced circulatory problems, as determined by direct intra-aortic determinations of blood pressure via umbilical arterial catheters. No systematic examination of radiographs was made to determine the incidence of bronchopulmonary dysplasia in surviving infants in group 2 . Therefore, the incidence of this complication cannot be compared between the two groups.

\section{Discussion}

This study has shown certain advantages in the use of pressure-limited ventilators for the management of infants with severe HMD. Infants in this group showed immediate and sustained improvement in oxygenation at a lower level of oxygen in the inspired air. This effect could be regarded as related to prolonged high positive pressure on the airways improving ventilation-perfusion relationships. The improved oxygenation obtained may also occur as a result of the increased $I: E$ ratio which allows for recruitment of alveoli with varying time constants. While the volume-cycled ventilators have been shown rapidly to correct the respiratory failure component, the rapidity of the cycle clearly does not allow enough time for the recruitment of areas with altered time constants to occur. On the other hand, because of the effects on the circulation of increased prolonged pressures delivered to the airways by the pressure-limited method, the improvement in ventilation that resulted in a lowering of $\mathrm{PaCO}_{2}$ similar to that achieved by the volumecycled respirator and the lack of obvious circulatory effects, might not have been anticipated.

A definite statement on the effects of the pressurelimited and volume-cycled respirators on the complication of bronchopulmonary dysplasia cannot be made. None of the survivors in either group had the condition radiologically. However the appearance of the pathological changes of BPD in the lungs of the 5 infants who did not survive with the volumecycled method, suggests that the pressure-limited approach may be effective in reducing this complication, and it seems to reduce the complication of pleural air leaks. Subsequent experience with this respiratory technique confirms this and pleural air leaks have been virtually eliminated from the nursery. Clearly patient survival is significantly greater with the pressure-limited technique, related in part, at least, to the decreased incidence of pleural air leaks and to improved oxygenation. The limitation of peak airways pressure provided by this method would appear to be the only factor responsible for the improvement. Although the numbers of patients studied were small, differences both in survival and oxygenation in both groups were so obvious as to preclude pursuing the study further.

Supported in part by Grants Nos. 5 RO1 HD 02644-09 (NIH), 5 RO1 HD 09067-02 (NIH), and 5 RO1 HD 07965-02 (NIH).

\section{References}

Berg, T. J., Pagtakhan, R. D., Reed, M. H., Langston, C., and Chernick, V. (1975). Bronchopulmonary dysplasia and lung rupture in hyaline membrane disease: influence of continuing distending pressure. Pediatrics, 55, 51-54.

Herman, S., and Reynolds, E. O. R. (1973). Methods of improving oxygenation in infants mechanically ventilated for severe hyaline membrane disease. Archives of Disease in Childhood, 48, 612-617.

Keuskamp, D. H. G. (1974). Ventilation of premature and newborn infants. International Anesthesia Clinics, 12, 281-307.

Correspondence to Dr Peter A. M. Auld, The New York Hospital, The Perinatology Center, 525 East 68th Street, New York, NY 10021, USA. 